\title{
Multiple Acute Ischemic Strokes in a COVID-19 Patient: a Case Report
}

\author{
Davide Cerasti ${ }^{1}$ (ID $\cdot$ Francesca Ormitti $^{1} \cdot$ Stefano Pardatscher ${ }^{1} \cdot$ Laura Malchiodi $^{2} \cdot$ Edoardo Picetti $^{2}$. \\ Roberto Menozzi ${ }^{1} \cdot$ Sandra Rossi ${ }^{2}$
}

Accepted: 25 June 2020 / Published online: 4 July 2020

(C) Springer Nature Switzerland AG 2020

\begin{abstract}
We describe a case of a 47-year-old Italian, immunocompromised, and obese woman infected by COVID-19 presenting with fever $\left(39.6{ }^{\circ} \mathrm{C}\right)$ and respiratory symptoms. Neurological examination was normal. Chest CT findings consist of bilateral interstitial pneumonia (visual score extension: $30 \%$ ). The patient was treated with antiviral drugs and anti-inflammatory drugs with supportive care. Seven days after admission to Covid-19 Unit, the patient rapidly developed worsening respiratory failure and acute respiratory distress syndrome (ARDS). She suddenly developed partial left hemispheric syndrome. A new HRCT scan of her thorax revealed diffuse ground-glass opacities in both lungs (visual score extension: $90 \%$ ). Brain CT performed $2 \mathrm{~h}$ after sudden-onset left-sided weakness showed subtle low attenuation within the right insular ribbon and frontal lobe (ASPECT Score 8). Multiphasic CT angiography (MCTA) demonstrated occlusion of both the dominant inferior division of the right middle cerebral artery and the A2 segment of the right anterior cerebral artery. After $24 \mathrm{~h}$, her pupils became dilated and unreactive, and brain CT demonstrated large bilateral infarctions of both the cerebellar and cerebral hemispheres. She had a rapid progression of interstitial pneumonia from COVID-19, developed multiple strokes, and died 1 day later. SARS-CoV-2 infection seems to predispose pluripathological subjects to cerebrovascular complications.
\end{abstract}

Keywords COVID-19 · Stroke · Antiphospholipid syndrome $\cdot$ Obesity $\cdot$ Case report

\section{Introduction}

A new type of pneumonia caused by the 2019 novel coronavirus (2019-nCoV) broke out in December 2019 in Wuhan City, China $[1,2]$. Before long spread to Europe, Northern Italy has become one of the areas of highest incidence, and Parma was located in the "red zone" for the Italian outbreak. As of June 5, 2020, the SARS-CoV-2 epidemic has caused 234,531 confirmed infections with 33,734 deaths in Italy. The clinical spectrum ranges from asymptomatic infection to severe pneumonia, leading to intensive care unit admission. We herein report the clinical spectrum, neuroimaging findings,

This article is part of the Topical Collection on Covid-19

Davide Cerasti

davidecerasti@gmail.com

1 Diagnostic Department, Neuroradiology Unit, University Hospital of Parma, via Antonio Gramsci, 1443126 Parma Italy

2 Department of Emergency, Anesthesia and Intensive Care Unit, University Hospital of Parma, Parma Italy and outcome of a patient developing acute stroke during COVID-19 infection.

\section{Case Presentation}

On March 14, 2020, a 47-year-old obese (BMI:31) woman, affected by antiphospholipid syndrome, was admitted to our Emergency Room (ER) (Parma University Hospital, EmiliaRomagna, Italy) with 6-day history of high-grade fever, cough, and fatigue for 1 week.

Physical examination revealed a body temperature of $39.6{ }^{\circ} \mathrm{C}$, blood pressure of $180 / 100 \mathrm{mmHg}$, pulse of 66 beats per minute, respiratory rate of 16 breaths per minute, and blood oxygen saturation of $93 \%$ on room air. Bilateral coarse breath sounds with wet rales distributed at the bases of both lungs were heard on auscultation.

A thoracic high-resolution computerized tomography (HRCT) scan showed bilateral ground-glass opacities in the lower lobes, especially the left one (visual score extension: $30 \%$ ), indicating the possibility of a viral interstitial pneumonia (Fig. 1a and b). 
Laboratory tests showed leukopenia (white blood cell count, 7600 per $\mathrm{mm}^{3}$ ). The white blood cell differential count displayed 5.4\% lymphocytes. Several additional laboratory tests were obtained, including $\mathrm{C}$-reactive protein, that was normal.

Her nasopharyngeal and oropharyngeal swab sampled for SARS-CoV-2 were reported back as positive later that day.

The patient was treated with antiviral drugs (ganciclovir, oseltamivir, Rezolsta) and anti-inflammatory drugs (meropenem, linezolid), with supportive care from March 20, 2020.

Seven days after admission to Covid-19 Unit, the patient rapidly developed worsening respiratory failure and acute respiratory distress syndrome (ARDS). Her left limbs became flaccid, and she suddenly developed partial left hemispheric syndrome.

A new HRCT scan of her thorax revealed diffuse groundglass opacities and consolidation in the dependent segments of both lungs (visual score extension: 90\%) (Fig. 1c and d). A small amount of pleural effusion was also seen.

Brain NCCT performed $2 \mathrm{~h}$ after sudden-onset leftsided weakness (Fig. 2a and b) showed subtle low attenuation within the right insular ribbon and frontal lobe (ASPECT Score 8).

MCTA demonstrated occlusion of both the dominant inferior division of the right middle cerebral artery and the A2 segment of the right anterior cerebral artery; intracranial collaterals were "poor" $(<50 \%$ of the MCA territory).

Due to the instability of the patient's condition after intubation, it was not possible to perform mechanical thrombectomy (MT).

After $24 \mathrm{~h}$, her pupils became dilated and unreactive, and brain CT demonstrated large bilateral infarctions of both the cerebellar (not shown) and cerebral hemispheres (Fig. 2c and d). She died 1 day later.

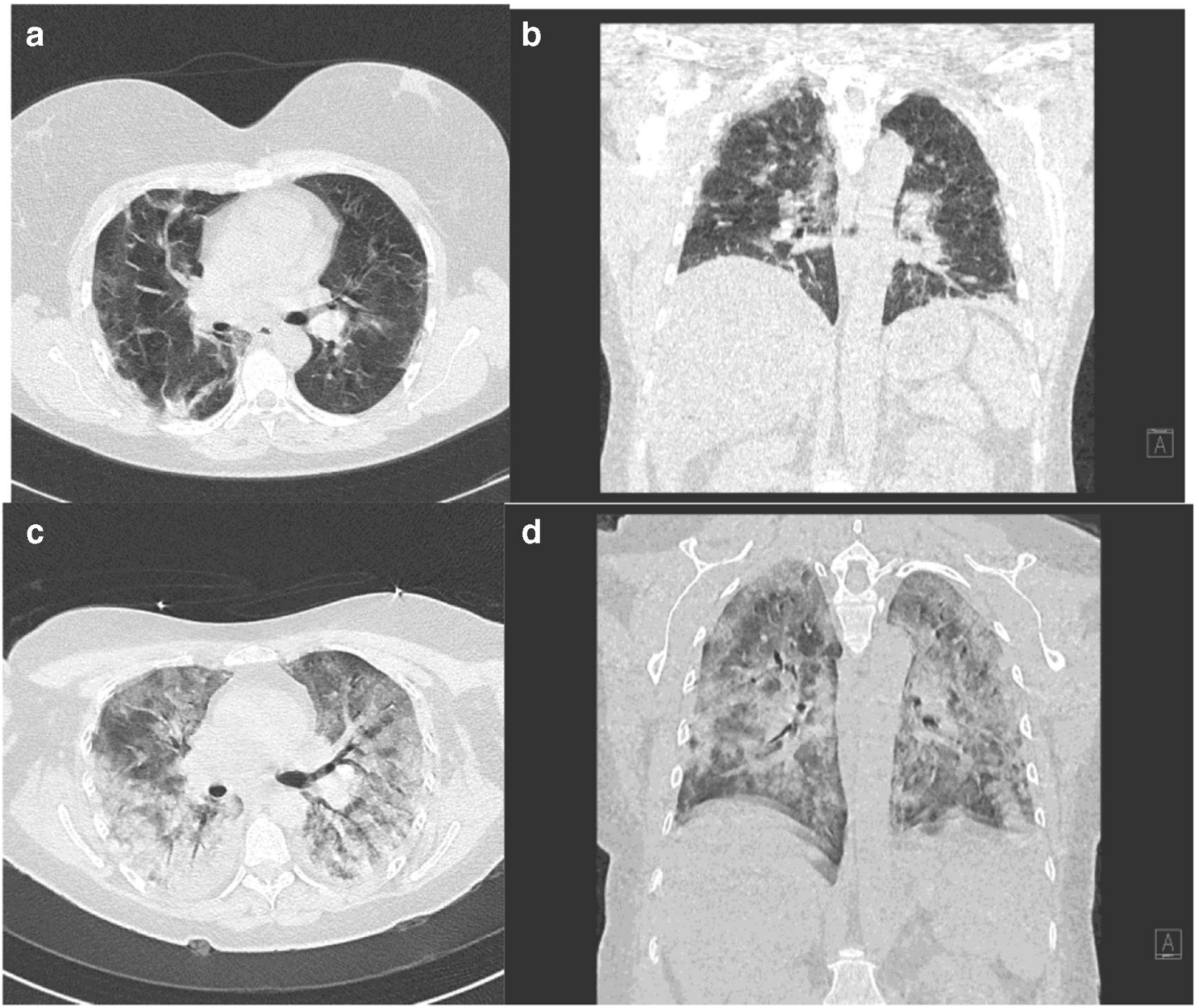

Fig. 1 Axial image (a) and 2D coronal image reconstruction (b). Highresolution chest-computed tomography on admission showed patchy ground-glass opacities (GGO). Consolidation was present in the dependent segments of both lungs with an asymmetric distribution, predominantly involving the left lower lobe. Distribution of lesions was mainly located in the medial lung. Acute CT axial (c) and image 2D coronal image reconstruction (d), of 7 days after admission, revealed marked progression of multiple, diffuse, and confluent GGO, even evolved into consolidation. Newly GGO were also distributed along peripheral or subpleural regions. A small amount of pleural effusion was also seen 


\section{Discussion and Conclusions}

To our knowledge, there have been few reports of multiple cerebral arterial ischemic strokes in novel coronavirus (2019nCoV) pneumonia patients [3-7]; although a recent Chinese study has demonstrated that acute cerebrovascular disease is not uncommon in COVID-19 patient [3]. They reported 221 patients with COVID-19, 11 of (5\%) whom developed acute ischemic stroke, $1(0-5 \%)$ cerebral venous sinus thrombosis (CVST), and $1(0-5 \%)$ cerebral hemorrhage. In their results, they emphasized that neurological COVID-19 patients were older and had multiple risk factors, more severe SARS-CoV-2 infection, and inflammatory response in the state of blood hypercoagulable. However, also adult patient with the same risk factors, overweight or obesity, are at higher risk as in our case.

The association between Covid-19 and stroke might be coincidental, but large artery stroke was diagnosed also in five of 206 patients with SARS in Singapore [8].

Nevertheless, several critically ill Covid-19 patients treated at our hospital also had venous thromboembolism (including pulmonary embolism), and, at least, six patients had acute ischemic strokes.

The high incidence of thrombotic complications also while on therapeutic doses of low molecular weight heparin (LMWH) and the presence of a pattern of large vessel ischemic strokes suggests that a pro-coagulant state could be present in Covid-19 patients.

Other viral infections, such as varicella zoster [9], cytomegalovirus [10], parvovirus [11], and human immunodeficiency virus have been associated with stroke.

Various hypotheses have been suggested to explain the apparent link between viruses and cerebrovascular disease documented in animal viral infections.

This may support the theory that $2019-\mathrm{nCoV}$ is an evolution of an unidentified animal virus.

The majority of viruses that have caused recent epidemics, with high lethality rates in people, are zoonoses originating from bats. Many of these viruses, including Coronaviruses, implicate the host response as an important contributor to the disease process; in this respect, dysregulated and excessive innate immune responses appear particularly important
Fig. 2 Hypoattenuation within the right insular ribbon (a) and the right frontal convexity (b). Follow-up scan at $24 \mathrm{~h}$ (c and d) showed clear hypoattenuation within the right and left hemispheres

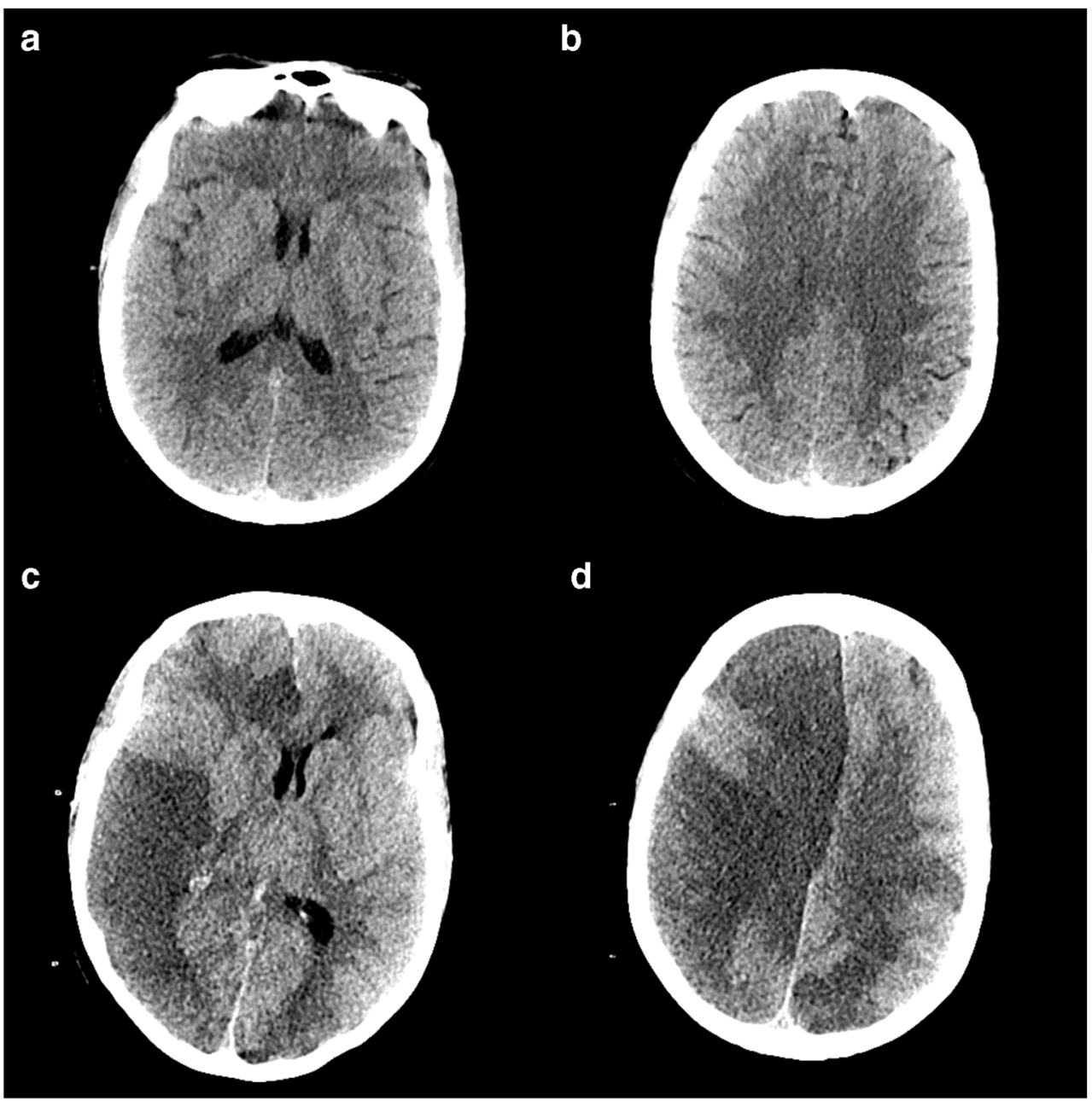


drivers of tissue damage during infection. It has been postulated that the reason why bats are the natural, healthy reservoir of these viruses may reside in their immune tolerance $[12,13]$. These aspects may occur pertinent when it comes to infection of an immunocompromised host, potentially protected by a weaker immune response against the infection.

Like the SARS coronavirus and herpes simplex, the 2019-nCoV may have an effect to reduce heparin sulfate, anti-thrombin III binding, prostacyclin, and thrombomodulin and enhance thrombin formation and platelet binding.

Furthermore, the WHO and the Centers for Disease Control and Prevention (CDC) survey revealed that $76.5 \%$ of critically ill COVID-19 patients are overweight and over $60 \%$ of patients under intensive care are either overweight or morbidly obese. Again, obesity can increase inflammation state and pressure on the lung; also, patients with obesity who require intensive care present challenges in management as it is more difficult to obtain diagnostic imaging, patients are more difficult to intubate, and they may not do well when prone.

In this case, it was not possible to perform mechanical thrombectomy (MT) because the patient had a significant hemodynamic instability. However, in our initial series of six COVID-19 patients with stroke, MT was successfully performed in two cases of right middle cerebral artery occlusion $[14,15]$.

During the pandemic, there was a reduction in hospital admissions for minor strokes, because the population was afraid of the COVID-19 and did not turn to the emergency service. The preparation times for the patient and the angiography room were longer due to the use of individual protection devices [15-18].

The assessment of acute stroke patients was performed by CT: brain NCCT, MCTA, and perfusion CT (PCT) in accordance with the guidelines $[4,15,18,19]$.

Intravenous thrombolysis was not performed because in those dramatic moments, international guidelines were not available $[7,15,20]$ and the risk of further bleeding (e.g., hemoptysis) was high.

Finally, a recent report highlights a close correlation between antiphospholipid syndrome, severe acute respiratory syndrome coronavirus 2 (SARSCoV-2) infection, and multiple ischemic strokes [6].

In summary, we report a 2019-nCoV immunocompromised patient with comorbidity who developed multiple acute ischemic strokes.

Although we cannot be certain of the contribution of Covid-19 to the development of stroke, we believe our experience should alert others managing critically ill $2019-\mathrm{nCoV}$ patients in future outbreaks to be vigilant against an increase in thrombotic complications including stroke.

\section{Compliance with Ethical Standards}

Conflict of Interest The authors declare that they have no conflicts of interest.

Ethical Standards All procedures were performed in accordance with the institutional ethics committee.

Patient Consent Full written informed consent was given by the patient prior to examination.

\section{References}

1. World Health Organization. Novel coronavirus-China. http:// www.who.int/csr/don/12-january-2020-novel-coronavirus-china/ en. Published January 12, 2020.

2. World Health Organization. WHO/novel coronavirus-China. Geneva: World Health Organization; 2020.

3. Yifan Zhou, Wei Li, David Wang, Ling Mao, Huijuan Jin, Yanan Li, Candong Hong, Shengcai Chen, Jiang Chang, Quanwei He, Mengdie Wang, Bo Hu. Clinical time course of COVID-19, its neurological manifestation and some thoughts on its management. Stroke \& Vascular Neurology 2020;0. https://doi.org/10.1136/svn2020-000398

4. Jain R, Young M, Dogra S, Kennedy H, Nguyen V, Jones S, et al. COVID-19 related neuroimaging findings: a signal of thromboembolic complications and a strong prognostic marker of poor patient outcome. J Neurol Sci. 2020;414:116923.

5. Morassi M, Bagatto D, Cobelli M, D’Agostini S, Gigli GL, Bnà C, et al. Stroke in patients with SARS-CoV-2 infection: case series. J Neurol. 2020. https://doi.org/10.1007/s00415-020-09885-2.

6. Zhang Y, Xiao M, Zhang S, Zhang S, Li Y, et al. Coagulopathy and antiphospholipid antibodies in patients with Covid-19. N Engl J Med. https://doi.org/10.1056/NEJMc2007575.

7. Oxley TJ, Mocco J, Majidi S, Kellner CP, Shoirah H, Singh IP, et al. Large-vessel stroke as a presenting feature of Covid-19 in the young. N Engl J Med This case was published on April 28, 2020, at NEJM.org. https://doi.org/10.1056/NEJMc2009787.

8. Dalakas MC, Clark WM. Strokes, thromboembolic events, and IVIg: rare incidents blemish an excellent safety record. Neurology. 2003;60(11):1736-7.

9. Ichiyama T, Houdou S, Kisa T, Ohno K, Takeshita K. Varicella with delayed hemiplegia. Pediatr Neurol. 1990;6:279-81.

10. Koeppen AH, Lansing LS, Peng SK, Smith RS. Central nervous system vasculitis in cytomegalovirus infection. J Neurol Sci. 1981;51:395-410.

11. Guidi B, Bergonzini P, Crisi G, Frigieri G, Portolani M. Case of stroke in a 7-year-old male after parvovirus B19 infection. Pediatr Neurol. 2003;28:69-71.

12. Mandl JN, Ahmed R, Barreiro LB, Daszak P, Epstein JH, Virgin HW, et al. Reservoir host immune responses to emerging zoonotic viruses. Cell. 2015;160:20-35.

13. D'Antiga L. Coronaviruses and immunosuppressed patients. The facts during the third epidemic. Liver Transpl. 2020:7150-3148. https://doi.org/10.1002/lt.25756

14. Yang B, Wang T, Chen J, Chen Y, Wang Y, Gao P, et al. Impact of the COVID-19 pandemic on the process and outcome of thrombectomy for acute ischemic stroke. J NeuroIntervent Surg. 2020;12:1-5. https://doi.org/10.1136/neurintsurg-2020-016177.

15. Qureshi AI, Abd-Allah F, Alsenani F, Aytac E, Borhani-Haghighi A, Ciccone A, Gomez CR, Gurkas E, Hsu CY, Jani V, Jiao L, Kobayashi A, Lee J, Liaqat J, Mazighi M, Parthasarathy R, Steiner T, Suri MFK, Toyoda K, Ribo M, Gongora-Rivera F, 
Oliveira-Filho J, Uzun G, Wang Y. Management of acute ischemic stroke in patients with COVID-19 infection: report of an international panel. Int J Stroke. Article reuse guidelines: sagepub.com/ journals-permissions. https://doi.org/10.1177/1747493020923234. journals.sagepub.com/home/wso.

16. Kerleroux B, Fabacher T, Bricout N, Moïse M, Testud B, Vingadassalom S, et al. Mechanical thrombectomy for acute ischemic stroke amid the COVID-19 outbreak decreased activity, and increased care delays. Stroke. 2020;51. https://doi.org/10.1161/ STROKEAHA.120.030373.

17. Pedicelli A, Valente I, Pilato F, Distefano M, Colosimo C. Stroke priorities during COVID-19 outbreak: acting both fast and safe. J Stroke Cerebrovasc Dis. 2020:104922 1 (in press).

18. Baracchini C, Pieroni A, Kneihsl M, Azevedo E, Diomedi M, Pascazio L, et al. N M Bornstein, L Csiba, J Valdueza, G Tsvigoulis, B Malojcic, ESNCH acute stroke education and guidelines working group Practice recommendations for the neurovascular ultrasound investigations of acute stroke patients in the setting of COVID-19 pandemic: an expert consensus from the
European Society of Neurosonology and Cerebral Hemodynamics. Eur J Neurol. 2020. https://doi.org/10.1111/ene.14334.

19. Jain R, Young M, Dogra S, Kennedy H, Nguyen V, Jones S, et al. COVID-19 related neuroimaging findings: a signal of thromboembolic complications and a strong prognostic marker of poor patient outcome. J Neurol Sci. 2020;414:116923. https://doi.org/10.1016/j. jns.2020.116923 Received 13 May 2020; Accepted 14 May 2020.

20. Oliver C, Co C, Yu JRT, Laxamana LC, David-Ona DIA. Intravenous thrombolysis for stroke in a COVID-19 positive Filipino patient, a case report. J Clin Neurosci. https://doi.org/10. 1016/j.jocn.2020.05.006.

We dedicate this case report to our colleagues who died of Covid-19.

Publisher's Note Springer Nature remains neutral with regard to jurisdictional claims in published maps and institutional affiliations. 